\title{
Dry matter accumulation and sheep grazing preference of six winter active annual legumes
}

\author{
M.G. HYSLOP, M.W.A. SLAY AND C.A. MOFFAT \\ AgResearch Lincoln, PO Box 60, Lincoln. \\ mark.hyslop@heinz.co.nz
}

\begin{abstract}
Winter active legumes are suited to the mild winter areas of New Zealand, where they provide high quality forage in late winter and early to mid-spring. Six winter active annual legumes, persian clover, balansa clover, sweet clover, hybrid serradella, subterranean clover, and Medicago truncatula, were sown in a randomised complete block design with four replicates. Their dry matter (DM) accumulation and grazing preference to young sheep were measured every 3-6 weeks from sowing on 6 April 2000 until 24 October 2000. Total ungrazed DM production ranged from $5500 \mathrm{~kg} / \mathrm{ha}$ (sweet clover) to $9300 \mathrm{~kg} / \mathrm{ha}$ (balansa clover) over this period. The seasonal pattern of growth varied significantly between species, as did hogget grazing preference, with persian, balansa, and subterranean clover most preferred. These six plant species are capable of producing large amounts of high quality dry matter, but at all grazings, preference was extreme (measured by the number of sheep preferring to graze any one of the species when given a choice of all six), which may indicate the limited usefulness of some species.
\end{abstract}

Key words: accumulative yield, grazing preference, Medicago truncatula, Melilotus albus, Ornithopus sativus $\mathrm{x}$ compressus, seasonal growth, sheep, Trifolium balansae, Trifolium respinatum, Trifolium subterraneum, winter active legumes

\section{Introduction}

Winter active legumes are suited to mild winter areas of New Zealand (Douglas 1993) with free draining soils that often have dry summers. These characteristics restrict productive farming to the autumn, winter, and spring seasons. Annual legumes can provide forage in winter and early to mid-spring (Taylor et al. 1977; Taylor et al. 1979). Under the correct management, large quantities of high quality forage that is high in carbohydrate (high digestibility) Taylor et al. 1977 can be produced (Taylor et al. 1979) in late winter, unlike perennial ryegrass-based swards in that period. These legume types are not widely used (except for subterranean clover) in New Zealand farming systems, possibly due to seed availability, current farming systems, and suitability to a limited geographic area. As farming systems become more specialised, there is an ever increasing need to grow specific forage crops to fit these systems, with annual forage plants providing large blocks of forage, often when perennial species cannot (Rys et al. 1988). There has been limited research conducted on these winter active annual legume species, with most occurring at the plot scale without animals, or for high country revegetation (Taylor et al. 1979; Wills 1983). Data are lacking on the seasonal growth pattern, total yield and grazing preference of currently available species of these legumes under New Zealand farm conditions. This trial aimed to collect data to gauge the suitability of six winter active annual legumes for use in finishing late, heavy lambs, or early pre-weaned spring lambs in a creep management system where only lambs have access to the legume.

\section{Materials and methods}

\section{Experimental site}

The experiment was conducted in the winter/spring of 2000 at the AgResearch Poukawa Research Station, Hastings, New Zealand (39 $\left.45^{\prime} \mathrm{S}\right)$. This Station consists of flat to gently rolling hill country with a sandy loam soil type, and an average annual rainfall of $771 \mathrm{~mm}$. Summers are predominantly dry, resulting in drought conditions every 3 to 4 years. Soil fertility levels (31 March 2000) were pH 6.1, Olsen P 21, potassium 7 , sulphur 8 , and no fertiliser was applied at any stage during the trial.

\section{Trial design and establishment}

The trial design was a randomised complete block with four replicates of each treatment $(2.05 \mathrm{~m}$ x $50 \mathrm{~m}$ plots). An overlaid split block grazing treatment was randomly allocated to one half of each block. On the ungrazed half of each block, cumulative dry matter cuts were taken over time to measure growth rhythm.

The trial site was grazed, then sprayed on 25 February 
2000 with 5 l/ha of Glyphosate (containing $360 \mathrm{~g} / \mathrm{l}$ of glyphosate as an isopropylamine salt) in $250 \mathrm{l} / \mathrm{ha}$ of water, conventionally cultivated (ploughed, disced, rolled) to a fine, firm seed bed, and drilled on 6 April 2000 using a Duncan fluted roller drill. Sowing rates were adjusted for germination and thousand seed weight (Table 1) to sow 250 viable seeds $/ \mathrm{m}^{2}$, with the aim of a final population of 150 plants $/ \mathrm{m}^{2}$ at 6 weeks of age. Once established, the experiment was not sprayed with herbicides.

each block dissected into leaf and petiole, stem, dead herbage, and weeds.

All forage samples were washed, then oven dried at $80{ }^{\circ} \mathrm{C}$ for 24 hours.

\section{Animals and grazing}

Thirty Romney cross ewe hoggets with a mean live weight of $48 \mathrm{~kg}$ (on 15 July 2000) were selected from a mob of 200, and treated with an oral anthelmintic for the control of internal parasites at the start of the first grazing preference period (17 July 2000), and again in the middle of the trial period (4 September 2000). The animals were pre-exposed to all forage treatments for 3 days prior to the start of the first grazing preference measurement period. This was done by allowing the animals to graze a nonmeasurement area at the end of each block, so that the animals became used to having a choice of

\section{Measurements and management}

\section{Establishment counts}

Establishment counts were conducted on 5 May 2000 and 8 June 2000 by randomly placing $20,0.25 \mathrm{~m}^{2}$ quadrats in each plot and counting the emerged seedlings.

\section{Forage mass and composition}

Forage dry matter (DM) was measured in the ungrazed areas of each block approximately every 3 weeks from July to November on 13 July 2000, 14 August 2000, 6 September 2000, 24 September 2000, and 24 October 2000. Measurements were made by cutting to ground level two $0.25 \mathrm{~m}^{2}$ quadrats randomly placed at successive $3 \mathrm{~m}$ intervals (always on a previously uncut area) along each plot, at each measuring date, (8 cuts per treatment per measuring date). A paired cut was also taken to ground level beside each forage mass cut to determine forage composition. Samples were then bulked, and a subsample from each treatment in diet and had experienced each forage treatment. Between preference measurements, animals were returned to perennial ryegrass/white clover swards for grazing.

Each block of the trial was fenced with flexi-nets and grazed separately with the 30 selected animals. Once placed inside a block, each animal was free to move and graze whichever treatment it wanted for as long as it wanted. A measurement of forage preference was gained by recording how many animals were grazing on each treatment at 5-minute intervals over a 2-hour period. Animals that were not actively grazing at each measurement time (e.g. sitting) were not recorded. After the first 2-hour measurement period (block 1), the animals were removed from the trial site to a bare ground area for 3 hours, then returned to the site to graze the next block (block 2). Blocks 3 and 4 were grazed the following day.

The grazing preference measurement periods were conducted whenever the shortest treatment reached 
$100 \mathrm{~mm}$ in height (approximately monthly from July), and animals were removed before the closest grazed treatment reached $50 \mathrm{~mm}$ in post-grazing height, regardless of the post-grazing heights of the other treatments. Fifty measurements of pre-grazing height were taken per plot before each grazing preference measurement period using a sward stick. Plots were grazed block by block with 150 other animals immediately after each grazing preference measurement period until the closest grazed treatment reached $50 \mathrm{~mm}$ in post-grazing height (using this method, an even post-grazing height of $50 \mathrm{~mm}$ was achieved across treatments). No mechanical trimming took place, so any difference in height was carried over to the next grazing measurement period.

\section{Analysis}

All analyses were performed using the statistical package Genstat 5 (Payne 1993).

An analysis of variance was performed on forage mass, forage composition, pre-grazing heights, and grazing preference data for a randomised complete block design.

Grazing preference data assumed a Poisson distribution model, where as all other data were normally distributed. Treatment means were separated using least significant difference (1.s.d. $=0.05)$ or standard error of the mean (S.E.M.).

\section{Results}

\section{Establishment counts}

All treatments achieved or exceeded the desired 150 plants $/ \mathrm{m}^{2}$ final plant populations at 8 weeks after sowing (9 June 2000), except for Medicago truncatula, which differed $(\mathrm{P}<0.01)$ from the other treatments at 134 plants $/ \mathrm{m}^{2}$ (Table 1). Similar plant counts for all treatments were recorded at 4 weeks after sowing (8 May 2000).

\section{Forage mass, seasonal growth pattern, and composition}

Total ungrazed DM production ranged from 5500 $\mathrm{kg} / \mathrm{ha}$ (sweet clover) to $9300 \mathrm{~kg} / \mathrm{ha}$ (balansa) from sowing (6 April 2000) until the last measurement (16 October 2000), which resulted in yield differences $(\mathrm{P}<0.01)$ between treatments (Figure 1). Growth rates varied between species, with balansa the quickest to establish, and Medicago truncatula's daily growth rate exceeding $142 \mathrm{~kg} \mathrm{DM} /$ ha per day in late spring (October).

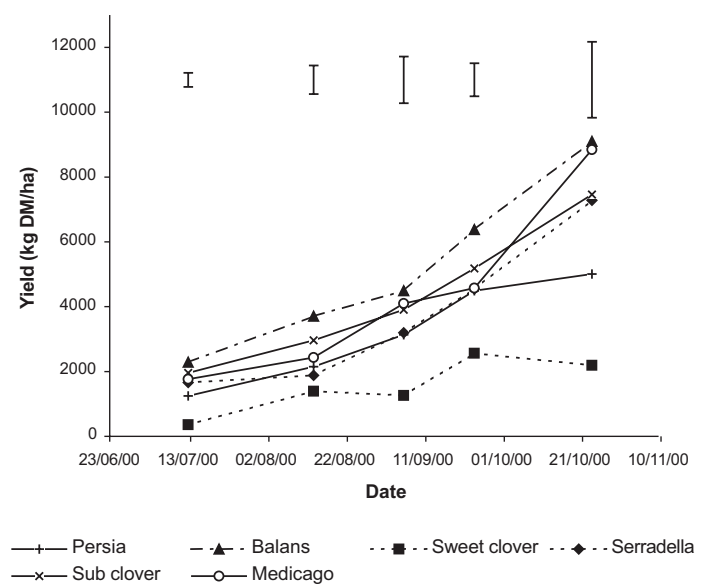

Figure 1 Ungrazed dry matter accumulation (kg $\mathrm{DM} / \mathrm{ha}$ ) of persian, balansa, sweet clover, serradella, subterranean clover, and Medicago truncatula winter annual legumes from 12 weeks after establishment to seed set. (I least significant difference $\alpha=0.005$ )

Botanical composition (percentage leaf, stem, dead, and other) between treatments varied $(\mathrm{P}<0.01)$ at each harvest date except for the final harvest on 16 October 2000 , when there were no significant differences in the percentages of leaf present across treatments (Figure 2). There were large differences over time in the percentage of stem in some species (Figure 3) as they (balansa, sweet clover, Medicago truncatula) entered a reproductive phase of growth.

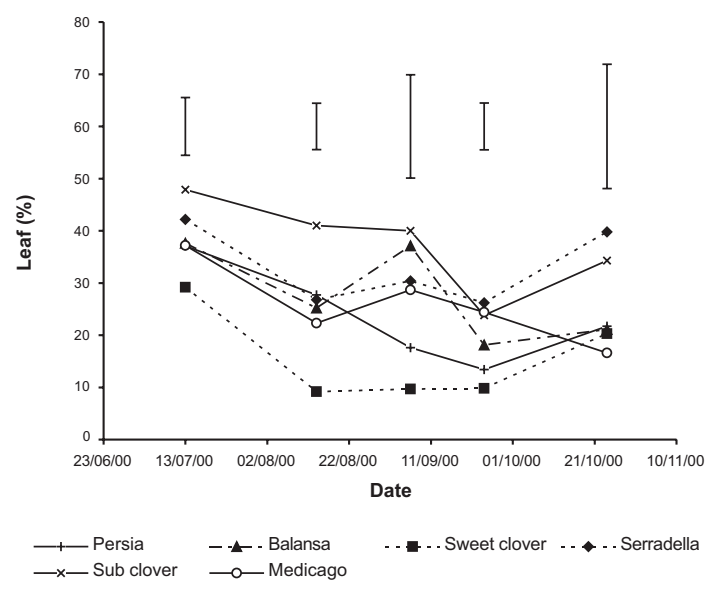

Figure 2 Percentage leaf of ungrazed pure swards of persian, balansa, sweet clover, serradella, subterranean clover, and Medic winter annual legumes from 12 weeks after establishment to seed set. (I least significant difference $\alpha=0.005$ ) 


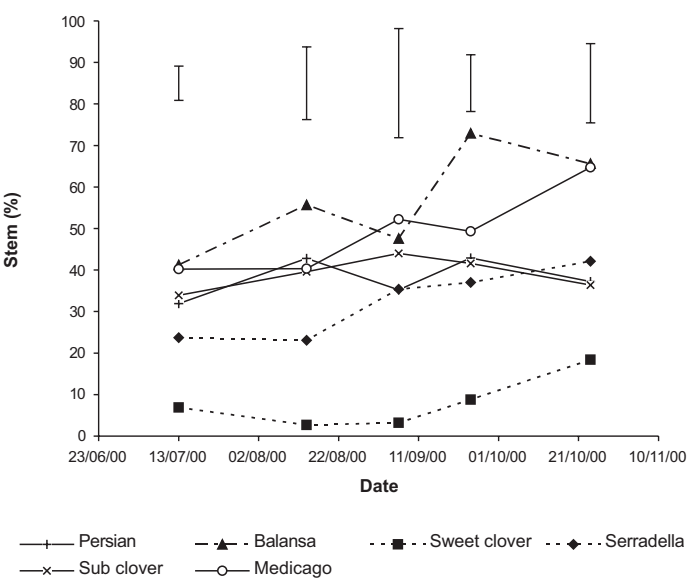

Figure 3 Percentage stem of ungrazed pure swards of persian, balansa, sweet clover, serradella, subterranean clover, and Medicago truncatula winter annual legumes from 12 weeks after establishment to seed set. (I least significant difference $\alpha=0.005$ )

Sweet clover had a large percentage of weeds present at all harvests as a percentage of total dry matter grown (range; 59-88\%) compared with the other five species, which averaged $22 \%$. Balansa and subterranean clover both had fewer $(\mathrm{P}<0.01)$ weeds present at all harvest dates, averaging $10 \%$ and $15 \%$, respectively. For all sown species, weed populations decreased over time as the sown species became more dominant.

\section{Grazing preference}

There was a difference $(\mathrm{P}<0.01)$ in hogget grazing preference between species at each measurement period. There was also a difference in species selection over time at later preference measurement periods as forage quality changed between species. balansa, persian clover, and subterranean clover were the most preferred species at all grazing preference measurement periods (Figure 4). There were no significant differences in pre-grazing heights across species at the start of each grazing preference measurement period.

\section{Discussion}

Our experiment shows that currently available cultivars of winter active annual legumes have the potential to be useful in farm systems through the accumulation of biomass over the winter and early spring period, just as early selections showed in the 1970s (Taylor et al. 1979). Conclusions from testing

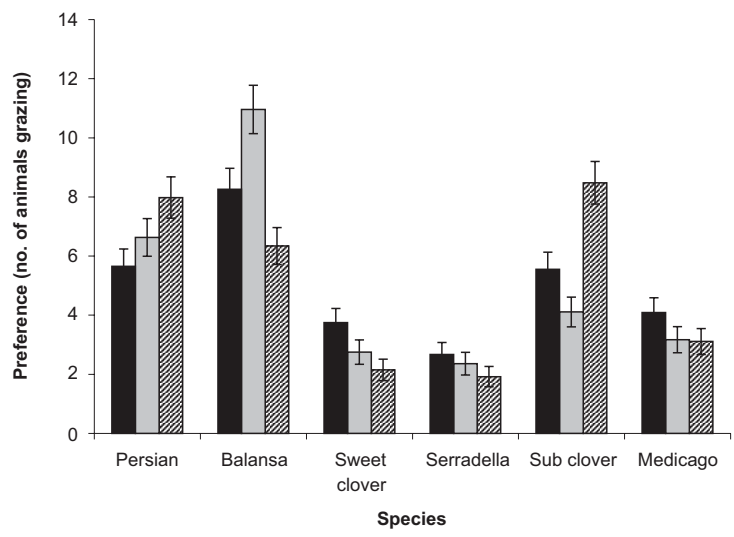

Figure 4 Grazing preference of 30 ewe hoggots offered swards of persian, balansa, sweet clover, serradella, subterranean clover, and Medicago truncatula winter annual legumes at three different grazing periods. (I least significant difference $\alpha=0.005$ )

these current selections are:

- Persian clover, subterranean clover, and balansa were highly preferred, while sweet clover, serradella and Medicago truncatula were avoided to some degree by young grazing sheep despite "looking like high quality dry matter".

- Persian clover, subterranean clover, Medicago truncatula and balansa produced large amounts of dry matter, while sweet clover and serradella were slow to establish and competed with weeds.

- The amount of quality dry matter produced by each species depended on the selection's inherent morphology of growth, particularly when each reached the reproductive phase of growth.

Forage grazing management from past grazings of other legume species has been shown to have a direct effect on animal preference and forage intake at subsequent future grazings (Curll et al. 1989), mainly due to changes in forage quality. While every effort in this experiment was made to eliminate any effects of forage quality on grazing preference between treatments (by using a large number of animals over a short period of time to graze the plots after each grazing preference measurement period), some differences in forage quality did occur. This was mainly because different species had different morphologies (i.e., subterranean clover and balansa have mature heights of 0.2 and $2 \mathrm{~m}$, respectively), and different flowering dates under the same grazing management in the same block. Fencing and grazing 
each treatment separately to the same post-grazing "state" across each block would partly solve this problem, but different amounts of stem, leaf and dead material would still be present.

Grazing management of these species had a large effect on regrowth level and potential despite the lax grazing strategy (down to $50 \mathrm{~mm}$ post-grazing height). The rate and amount of regrowth depended on if, or how much, each species regrew from nodal buds of stems that had been trampled to the ground by the grazing animal (balansa) or if growth had to be initiated mainly from new crown buds (persian clover). In an on-farm situation, ideal management decisions could be adopted to take regrowth down time into consideration, which highlights the need to sow these winter active annual legume species as a specialist crop so that best practice management can be implemented. This contrasts a mixed sward where one or several species in the mixture are compromised by the dominant species grazing strategy.

Other factors of animal acceptability are also involved in consumption levels of these legume species. Sweet clover, an aromatic compound (coumarin) lowers sheep grazing preference (Hoveland \& Townsend 1983), which may explain why, along with its high weed content, this was one of the least preferred species.

From field observation during this experiment, these winter active annual legumes would be more suited to resowing each year as a seasonal crop rather than leaving the plant to become reproductive and set seed. The loss in the quantity of quality forage for grazing was high in species that elongated as they became reproductive (persian clover, Medicago truncatula, and balansa). There was minimal forage loss in subterranean clover because its reproductive structures were predominantly produced below a mass of vegetative growth.

Further work is required to identify the ideal grazing management (frequency and intensity of grazing) for pure and mixed swards of these winter active annual legume species, as well as measurement of the resulting animal performance. Their practical performance in a farm system under set stocking or rotational grazing also requires further measurement.

\section{ACKNOWLEDGEMENTS}

The authors would like to thank the Poukawa AgResearch farm staff for their assistance with the experiment. The research was founded by the Foundation for Research, Science and Technology.

\section{REFERENCES}

Curll, M.L.; Jones, R.M. 1989. The plant-animal interface and legume persistence - an Australian perspective. pp 339-360. In: Persistence of forage legumes. Eds. Barns R.F., Brougham R.W., Clements R.J., Martin G.C., Matches A.G., and Sheath G.W. American Society of Agronomy, Inc., Crop Science Society of America, Inc., Soil Science Society of America, Inc.

Douglas, G.B. 1993. Alternative legume species in New Zealand: A review. pp 31-38. In: Proceedings of the Second National Alternative Pasture Legumes Workshop 1993.

Hoveland, C.S.; Townsend, C.E. 1985. pp. 147148. Other legumes. In: Forages. The science of grassland agriculture. Eds. Barnes R.F., Heath M.E., and Metcalfe D. S., Iowa State University Press, Iowa, U.S.A.

Payne, R.W. 1993. Genstat 5 Reference Manual, release 3. Lawes Agricultural Trust 1993. Clarendon Press, Oxford, U.K.

Rys, G.J.; Smith, N.; Slay M.W. 1988. Alternative forage species for Hawkes Bay. Proceedings of the New Zealand Grassland Association 18: 75-80.

Taylor, A.O.; Hughes, K.A.; Haslemore, R.M.; Holland, R. 1977. Influence of maturity and frequency of harvest on the nutritive quality of cool season forage legumes. Ibid 7: 45-49.

Taylor, A.O.; Hughes, K.A.; Hunt, B.J. 1979. Annual cool season legumes for forage. II. Seasonal growth patterns and effects of cutting frequency and cutting height on yield. New Zealand Journal of Experimental Agriculture 7: 149-152.

Wills, B.J. 1983. Forage plants for the semi- and high country and rangelands of New Zealand. In: Proceedings of the 1983 Hill and High Country Seminar. Lincoln College, Centre for Resource Management, Special Publication 26: 59-66. 
